quently the westerly winds must be at least twice as strong in January as in July, notwithstanding Dr. Newberry seems to think there may not be much difference. If the annual average velocity of wind. therefore, whatever it may be, causes a difference of level between America and France of 2.4 inches, then this difference in January is 3.2 inches, and in July only 1.6 inches, and consequently a change of difference of sea-level of 1.6 inches between the two seasons. The discussion of long series of tide observations on both sides of the Atlantic gives a small annual inequality of sea-level with a range of several inches; but both the ranges and the epochs of maximum height of sea-level are nearly the same on both sides, the latter occurring in the fall; and so there can be, at most, only a very small change between January and July, not possibly as much as 1.6 inches, and therefore the average wind of the year cannot cause a difference as great as 2.4 inches, deduced from the preceding argument upon the hypothesis that wind-friction is in proportion to the velocity. It is admitted that some of the data upon which these results are based are somewhat uncertain; but if some of them are in error, a fourth or even a third part, it affects the argument very little.

Upon the usual assumption that friction between the different strata of water is proportional to the relative velocities without regard to difference of pressure at different depths, it is readily inferred, from what precedes, that the absolute surface velo. city is independent of depth of water, and so a westerly wind of 40 miles an hour across the Atlantic would give rise to the same surface velocity as on Lake Erie. Dr. Newberry has not furnished us with any observation of surface velocity, and therefore we cannot infer what the velocity of surface water on the Atlantic, corresponding, say, to the average velocity of about 8 miles per hour, would be. This, if wind-îriction is proportional to the velocity, would be one-fifth of that on Lake Erie corresponding to a velocity of 40 miles per hour. If the wind does not blow the water against a barrier, but in circuits, of course the case is very different.

In the trade-wind latitudes the westerly component of motion is perhaps about the same as the easterly component of the middle latitudes in the North Atlantic; and, as the tropical sea between Africa and the Gulf of Mexico is much deeper, we may infer, from what precedes, that the trade-winds cannot possibly cause a difference of sea-level of two inches, and hence raise the level of the Gulf of Mexico as much as one inch above the normal undisturbed level. The winds, therefore, can have no sensible influence in producing the Gulf Stream, for this deep and rapid current can only be caused by a difference of sea-level between the Gulf and the parts in higher latitudes toward which it flows.

Wasbington, July 18.

WM. FERREL.

\section{Neff's gas-wells.}

In the geological map of Ohio, showing the positions of the oil and gas wells (Science, June 25, 1986), there is a circle enclosing these words. 'Neff's gaswells.' 'This region was discovered in 1864 as geologically, and in many particulars physically, the duplicate of the Venango county, Penn., region. In 1865 well No. 1 was bored, proving the substratification of the subcarbonifercus shales and sands to be the equivalents of those in Pennsylvania; but, in place of striking oil, there was developed a remarkable gas-well, which has been described by tourists and scientific men as a geyser of great violence. A full account of all the wells has been published in the Ohio state geological survey, and quite recently in the tenth volume of the Tenth census of the United States, by Prof. S. F. Peckham.

Some of the wells discharge a few gallons of oil each day, of a superior lubricating quality, gravity $32^{\circ}$.

The analysis of the gas is as follows :-

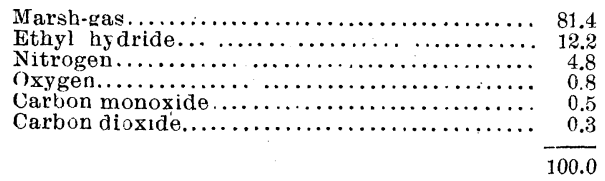

There is also a small amount of free hydrozen which is carburetted before burning.

The analysis of the carbon, known as an article of commerce by the trade-mark, 'Patented diamond black,' produced from the gas of these wells by patented processes granted the writer, is as follows : -

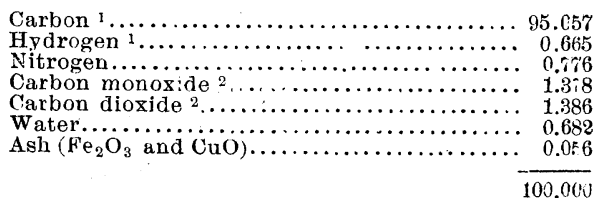

The pressure on these wells is not the same in all. There is a pressure for each well; at which degree of pressure there is an equilibrium between the generation or discharge of the gas, and the well's state of rest or quiet. Very little salt water is found in these wells, and it gives little trouble. Observations show that the supply increases in warm weather and in the heat of the day, and regularly with the variations of the moon, being strongest at the full moon. The gas is a rich illuminating hydro-carbonaceous gas, and, even when mixed with seven parts of atmospheric air, is a good illuminant. Well No. 2 has been systematically examined; and there is no apparent diminution in the supply of gas, during the past fourteen years of the twenty years the well has been 'blowing.' Where is it from?

That there is a limit to the supply of petroleum or gas cannot be questioned; but, with proper scientific and economical use of wells and territory, the life of a well can scarcely be measured or computed : it is too great in quantity, and too long in time.

Fresh water will 'drown out'a well. Will not holding a well under pressure until its equilibrium between a state of rest and production is about established, injure the well? It is an injury ; therefore transporting gas through long lines of pipe, by an initial potential force amounting to several hundred pounds' pressure at the wells, is not the correct way. There is a reduction of pressure of about eight pounds to the mile in pipes. For long distances it will be proven that gas can be blown more economically, and to better advantage to wells and transportation, through the pipes, than be forced by its

1 Including the $\mathrm{C}$ and $\mathrm{H}$ of 0.024 solid hydrocarbon.

2 These gases were doubtless partly formed from solid carbon and occluded oxygen by the heat applied in vacuo. 
initial pressure. The use of a fan-wheel may be applicable.

Although here, in and about this circle in the said map, no paying oil-well has been struck, nor does any great 'gas-gusher' 'blow,' yet good oil-sands, saturated with petroleum, are found, and a gas-belt is developed of most remarkable persistency and continuance; and the separated and scattered wells demonstrate a territory in which good paying oil and gas wells are liable any where to be struck. This territory embraces about the highest lands above Lake Erie, in the state of Ohio. This region gives proof of an abundance of gas for ages to come, for the supply of the surrounding manufacturing towns for light and heat.

The location of 'Neff's gas-wells' is in the eastern part of Knox and the western part of Coshocton counties, $\mathrm{O}$.

Gambier, Knox county, O., July 15.

\section{A remarkable swarm of Sciara.}

In Psyche for September, 1880, Dr. Hagen, in discussing a swarming species of Sciara from South Carolina. made the statement, based upon Weyenbergh's list of swarms of Diptera (Tijdskrift $v$. entom. 1861), that the swarming of Sciara is new. In the American naturaitist for February, 1881, Professor Riley states that he has frequently observed them in swarms so dense as to appear at a short distance like smoke, and quotes a letter from Dr. S. S. Rathvon concerning the swarming of a species of this genus in the upper room of a building in Bethlehem, Penn.. where they were observed to issue between the floor-boards. These records indicate that some interest will attach to the following facts :-

Tuesday evening, July 20, I was sitting in my library of the second floor, when I became conscious of a humming noise, as of a distant army of flies. The noise gradually increased for nearly balf an hour, when I went to the window to investigate. Outside I heard only the customary night noises; but, as I drew my head in, I saw that the ceiling of the library was covered with tens of thousands of minute midges of the genus Sciara. Except immediately above the lamp, the white ceiling was tinted brown with them. They made no attempt to reach the light, but clung to the ceiling around the edges of the room, extending down on the walls for several inches, and massed a dozen or more deep in the angles. All were in constant motion, and the noise was loud enough to drown the sounds of the crickets and tree-toads outside. The sound, as a whole, was a distinct musical note, varying but a fraction of a whole tone, and corresponded, as nearly as I could place it, with $\mathrm{E}$ flat above middle $\mathrm{C}$. The number was beyond compute. I at once closed the windows, and in ten minutes they became almost opaque from the numbers which settled upon them. On going below stairs, I found, that although doors and windows were open, and a bright light was burning, very few of the midges had entered. I easily rid the library of those which had entered, by lighting a spoonful of pyrethrum in my ash-receiver. They fell as fast as snowflakes, and in the morning were swept up by the dustpanful.

The house is a new one, finished in April last. and is situated on a level, nearly clear plateau on Washington Heights. The gnats entered only at the second- story windows. The night was clear and not sultry, and the wind was north-east. Later in the evening a heavy shower fell. The midges were not noticed on previous or succeeding nights. From these facts it seems quite plain that the gnats were flying in an immense swarm at some distance from the ground. and either met the house in the direct course of their flight, or were attracted from their regular route by the light. L. O. How ARD.

Washington, July 23.

\section{Another carnivorous rodent.}

Over a year ago I recorded in this journal the carnivorous habits of several of the Rodentia (Science, v. No. 114). In that communication I called attention to the meat-eating propensities of the muskrat (Fiber zibethicus), and a species of fieldmouse, that I then had in captivity. Since writing that, I have described the field-mouse, for it proved to be a now speeies, and it is now known as True's Piñon mouse (Hesperomys truei). No doubt others of the same genus will be found given to a similar diet when the opportunity offers. But here comes another rodent that strongly asserts his taste in that direction, and will consume raw meat even in prefer. ence to his regular diet list, as we have always conceived it to be. This is no less an animal than the 'prairie dog' (Cynomys ludovicianus). I have at the present writing a pair, half-grown, of these engaging little pets; and for the last two days they have been fed on raw meat, refusing their ordinary food served to them at the same time. They tell me that the Navajo Indians, when they keep them in captivity, feed them with raw meat half the time, and the little marmots eat it with avidity.

As I have noticed elsewhere, rats will devour raw meat whenever they can get it, and usually in prefer ence to other things.

In time, no doubt, it will be proved that it is a universal habit of the order Glires.

Fort Wingate, N. Mex., July 16.

R. W. SHUFELDT.

\section{Germ of hydrophobia.}

I see in your issue of July 9 , p. 23 , that the credit of having at last discovered the germ of hydrophobia is claimed by the London Lancet for Dr. Dowdeswell, who finds it in a micrococcus in the medulla and spinal cord of animals affected with this disease.

I do not remember that the attention of your readers has been drawn to the fact that this discovery had been previously claimed, with much show of reason, by Professor $\mathrm{H}$. Fol of Geneva (Archives des seiences, vol. xiv. p. 449,1885 , and vol. xv. p. 414, 1886). According to Fol, also, it is a micrococcus found only in this disease, and so minute that it requires a good $\frac{1}{12}$ objective to see it at all. Of this micrococcus he has made pure cultures, which by inoculation communicate the disease with certainty.

Berkeley, Cal., July 19

JoSEPH LECONTE.

\section{A bright meteor.}

The meteor recorded by Mr. Brackett as having been seen at St. Johnsbury, Vt., on the night of Aug. 11 , agrees as to size and direction, as well as date and time, with one seen at Salem, Mass. 